\title{
Video Article \\ Protocols for Testing the Toxicity of Novel Insecticidal Chemistries to Mosquitoes
}

\author{
Carlos A Brito-Sierra* ${ }^{1}$, Jasleen Kaur* ${ }^{1}$, Catherine A. Hill ${ }^{1,2}$ \\ ${ }^{1}$ Department of Entomology, Purdue University \\ ${ }^{2}$ Purdue Institute for Inflammation, Immunology and Infectious Disease, Purdue University \\ * These authors contributed equally
}

Correspondence to: Catherine A. Hill at hillca@purdue.edu

URL: https://www.jove.com/video/57768

DOI: doi:10.3791/57768

Keywords: Biology, Issue 144, Mosquito, Aedes aegypti, Anopheles gambiae, Culex quinquefasciatus, larvicide, adulticide, endectocide, bioassay, toxicity, $\mathrm{LC}_{50}$

Date Published: 2/13/2019

Citation: Brito-Sierra, C.A., Kaur, J., Hill, C.A. Protocols for Testing the Toxicity of Novel Insecticidal Chemistries to Mosquitoes. J. Vis. Exp. (144), e57768, doi:10.3791/57768 (2019).

\section{Abstract}

New classes of insecticides with novel modes of action are needed to control insecticide resistant populations of mosquitoes that transmit diseases such as Zika, dengue and malaria. Assays for rapid, high-throughput analyses of unformulated novel chemistries against mosquito larvae and adults are presented. We describe protocols for single point-dose and dose response assays to evaluate the toxicity of small molecule chemistries to the Aedes aegypti vector of Zika, dengue and yellow fever, the malaria vector, Anopheles gambiae and the northern house mosquito, Culex quinquefasciatus, on contact and via ingestion. As an example, we evaluated the toxicity of amitriptyline, a small molecule antagonist of $\mathrm{G}$ protein-coupled receptors, via larval, adult topical and adult blood-feeding assay. The protocols provide a starting point to investigate insecticide potential. Results are discussed in the context of additional experiments to explore product applications and mechanisms for delivery.

\section{Video Link}

The video component of this article can be found at https://www.jove.com/video/57768/

\section{Introduction}

Mosquitoes transmit the causative agents of infectious diseases that impact human health globally ${ }^{1}$. The three most important mosquito genera affecting human health are Aedes, Anopheles, and Culex. Species of Aedes mosquitoes vector the arboviruses that cause Zika, dengue, yellow fever and chikungunya. Anopheles species vector malaria parasites and Culex species transmit West Nile virus and filarial nematodes ${ }^{2}$. The World Health Organization (WHO) has called for the eradication of ten Neglected Tropical Diseases (NTD) by $2020^{3}$ and identified mosquito control as the most viable strategy. Insecticides are powerful tools to control mosquitoes and reduce disease transmission ${ }^{4,5}$. However, the emergence of insecticide-resistant mosquito populations threatens the continued control of many diseases ${ }^{6,7,8}$. The Innovative Vector Control Consortium (IVCC) has launched the first dedicated effort to develop replacement insecticides for mosquito control ${ }^{9}$. New insecticides with novel modes of action (MoA) are needed to meet WHO goals and achieve disease control. The discovery and development of new insecticide classes with novel MoAs require whole organism assays for rapid, high-throughput analysis of chemistries and in comparison to industry standards ${ }^{10}$.

Multiple assays are available to evaluate the repellency and toxicity of insecticides to larvae and adult mosquitoes, and some are suitable for the evaluation of novel formulated or unformulated chemistries. The WHO protocol ${ }^{11}$ is a contact assay used to test products against fourth instar larvae. Published studies also describe a variety of larval assays used to test the toxicity of small molecule chemistries to larvae of Aedes aegypti, Anopheles gambiae and Culex quinquefasciatus ${ }^{10,12,13,14,15,16}$. The Centers for Disease Control and Prevention (CDC) bottle bioassay is used to assess insecticide resistance in field caught populations of adult mosquitoes via evaluation of lethal concentration (LC) and lethal time (LT) in comparison to a standard diagnostic dose of a commercial insecticide ${ }^{17}$. The WHO susceptibility test offers another approach to evaluate insecticide resistance in adult mosquitoes whereby mosquitoes are exposed to insecticide-impregnated paper inside glass vials for $1 \mathrm{~h}$ and mortality is assessed at $24 \mathrm{~h}^{18}$. Other assays spray formulations inside sealed cages and record mosquito knockdown and death at desired timepoints ${ }^{19}$. Topical application to the mosquito thorax has been used to evaluate potency of different pesticides ${ }^{20}$. The Liverpool Insect Testing Establishment (LITE) ${ }^{21}$ employs Standard Operating Procedures to evaluate the bioactivity of chemistries to adult mosquitoes. The LITE adult topical assay applies a small volume of test product to the thorax of adult mosquitoes with mortality scored at $48 \mathrm{~h}$. The assay enables quantification of the dose received per individual mosquito ${ }^{21}$. The LITE tarsal assay evaluates the toxicity of test product to adult mosquitoes resting on a chemically treated surface and is used to identify chemistries with potential for development as indoor residual sprays (IRS) or use in insecticide treated bed-nets (ITNs) to control Anopheles mosquitoes.

The WHO and CDC assays have limitations for testing novel, unformulated chemistries, and the goal of the CDC bottle bioassay is evaluation of susceptibility over short assay periods (two hours) rather than toxicity ${ }^{22,23}$. In addition, assays for evaluating the toxicity of chemistries delivered 
in the blood meal and potential for development of systemic-acting products (i.e., endectocides) are lacking. Here, we describe assays for testing the mosquitocidal activity of novel chemistries that are soluble in water or one of several organic solvents against the larvae and adults of Aedes, Anopheles and Culex. First, we demonstrate a larval assay previously described by our group ${ }^{10,12,13,16}$, and performed here as (1) a screen to rapidly evaluate multiple chemistries at single point dose, and (2) a dose response assay to determine the lethal concentration (e.g., $\mathrm{LC}_{50}$, $\mathrm{LC}_{75}$ or $\mathrm{LC}_{90}$, ) of a single chemistry. Next, we describe two adult assays for determination of lethal dose (LD). The first of these is an adaptation of the LITE protocol for testing of topically applied, novel chemistries against adult mosquitoes in comparison to a positive control. The second is a feeding assay for the evaluation of chemistries delivered systemically via the blood meal.

\section{Protocol}

NOTE: All strains and reagents required for the work described in the following protocols, and suppliers are listed in the Table of Materials.

\section{Culture of Mosquito Larvae and Adults}

NOTE: Insecticide susceptible strains of mosquitoes are available from the Malaria Research and Reagent Reference Repository. Recommended strains are as follows: Aedes aegypti Liverpool (LVP) strain, Anopheles gambiae Kisumu (KISUMU1) strain and Culex quinquefasciatus Johannesburg (JHB) strain.

1. Culture mosquito larvae from eggs on a $12 \mathrm{~h}$ day $/ 12 \mathrm{~h}$ night cycle at $28{ }^{\circ} \mathrm{C}$ and $75-85 \%$ relative humidity $(\mathrm{RH})$ in $25 \mathrm{~cm} \times 40 \mathrm{~cm}$ plastic trays ( 400 larvae per tray) as described by Nuss ${ }^{29}$. Feed the larvae ground gerbil (A. aegypti and An. gambiae) or flake fish food (C. quinquefasciatus). For larval assays, collect larvae at the third larval (L3) instar stage.

2. Rear adult mosquitoes from pupae that have been transferred to plastic cups and place inside $20 \mathrm{~L}$ plastic cages in an insectary under the conditions described above. Maintain mosquitoes on $20 \%$ sugar solution as described elsewhere ${ }^{29}$. Collect adults at $3-5$ days post emergence.

\section{Larval Contact Assay (Single Point Dose or Dose Response Assay)}

NOTE: The assay can be conducted with chemistries that are soluble in water or dimethyl sulfoxide (DMSO), provided that the final concentration of DMSO in test wells does not exceed $1 \%$. Alternative solvents may be an option, but it is essential to first confirm that the final concentration does not cause more than $10 \%$ mortality at $72 \mathrm{~h}$ post exposure. The assay may be performed as a single point dose or dose response assay. If performing the latter, it is recommended to test a range of concentrations (minimum of five), spanning the expected $\mathrm{LC}_{50}$.

1. Label the wells of a clear 24-well tissue plate as shown in Figure 1.

2. Prepare a stock solution of the test chemistry in a $1.5 \mathrm{~mL}$ tube.

1. Weigh each chemistry using an analytical balance, and depending on solubility characteristics, re-suspend in sterile dd $\mathrm{H}_{2} \mathrm{O}$, $\mathrm{DMSO}$ or other suitable organic solvent of choice (see Figure 2).

NOTE: Calculations should take into account the purity of the chemistry. For example, for a chemistry that is $99 \%$ pure, dissolve 10.1 $\mathrm{mg}$ in $1,000 \mu \mathrm{L}$ of acetone to obtain a $1 \%$ solution. Seal with paraffin film and store at $-20^{\circ} \mathrm{C}$.

3. Determine the final concentration of the test chemistry that will be evaluated and prepare serial dilutions from the stock solution accordingly, using the appropriate solvent.

NOTE: The concentration and volume of chemistry and solvent can be calculated using the formula $C_{1}{ }^{*} V_{1}=C_{2}{ }^{*} V_{2}$ where $C_{1}=$ concentration of sample $1, C_{2}=$ concentration of sample $2, V_{1}=$ volume of sample 1 and $V_{2}=$ volume of sample 2 . See the example calculations shown in Figure 2 and Table 1.

1. Prepare a $10 \mathrm{mM}$ stock solution and serial dilutions as required to obtain desired test concentrations (Table 1B).

4. Using a wide-bore plastic transfer pipette, transfer five L3 larvae to the well of a tissue culture test plate; L3 larvae can be recognized by length $(\sim 2.5-3.5 \mathrm{~mm})$ and head capsule width of $\sim 0.025 \mathrm{~mm}^{24}$. Gently remove the water with a $1 \mathrm{~mL}$ pipette and replace with the desired volume of $\mathrm{ddH}_{2} \mathrm{O}$ (see below). Repeat to obtain $\mathrm{n}=4$ technical replicates per treatment (i.e., 20 larvae total per treatment).

5. Add the appropriate volume of test chemistry to each of the four replicate wells in the 24-well test plate and gently swirl the plate to ensure uniform mixing of chemistry. Place the plate in a test or growth chamber under constant conditions (e.g., $25^{\circ} \mathrm{C}$ and $\sim 75-85 \% \mathrm{RH}$ is recommended, and a $12 \mathrm{~h}$ light/12 $\mathrm{h}$ dark cycle if possible).

NOTE: For reproducibility between experiments, ensure subsequent assays are performed under the same environmental conditions.

6. Record the number of dead/non-responsive larvae in each well at $30 \mathrm{~min}, 1,1.5,2,3,24,48$ and $72 \mathrm{~h}$ post-exposure (or alternative time points) on the score sheet (Table 2). Gently tap the side of the plate. If no movement is observed, gently touch the larva with a sterile toothpick. Score larvae that do not respond to tapping/touch as "dead". NOTE: Other morphological and behavioral phenotypes may be observed and can be recorded.

7. Correct for control mortality using the modified Abbott's formula if desired, as follows: Mortality $(\%)=(X-Y) * 100 /(100-Y)$,

where $X=$ the percent mortality in the treated sample, and $Y=$ the percent mortality in the control.

8. Graph results as a histogram or logarithmic curve using software of choice such as Graph-pad Prism 6 or similar, and calculate Lethal Concentration (LC) values relative to the control.

9. Repeat the assay using a separate batch of mosquitoes to obtain $n=3$ or more biological replicates.

\section{Adult Topical Assay (Single Point Dose or Dose Response Assay)}

NOTE: The adult topical assay is conducted using acetone as a solvent. Alternative solvents may be an option, but it is essential to first confirm that the final concentration does not cause more than $10 \%$ mortality at $48 \mathrm{~h}$ post exposure. The assay may be performed as a single point dose 
or dose response assay and is used to determine lethal dose (LD). If performing the latter, it is recommended to test a range of concentrations (minimum of five), spanning the expected $L D_{50}$.

1. Determine the number of adult female mosquitoes required to complete the assay. NOTE: A point dose assay with a single chemistry will require a minimum of 90 mosquitoes ( 30 for the positive control, 30 for the acetoneonly negative control and 30 for the test chemistry).

2. Culture 3 to 5-day-old adult female mosquitoes and move to a separate $20 \mathrm{~mL}$ plastic bucket using an aspirator (Figure 3).

3. Label 9 oz paper cups with the name and concentration of the test chemistry. Set aside $10 \mathrm{~cm} \times 10 \mathrm{~cm}$ mesh squares and rubber bands for each cup (see Figure 4).

4. Select an existing insecticide as a positive control (e.g., the synthetic pyrethroid, bifenthrin) and prepare a $1 \%$ stock solution (10 $\mu \mathrm{g} / \mu \mathrm{L})$ in acetone.

NOTE: Calculations should take into account the purity of the chemistry. For example, for a chemistry that is $99 \%$ pure, dissolve $10.1 \mathrm{mg}$ in $1,000 \mu \mathrm{L}$ of acetone to obtain a $1 \%$ solution. Seal with paraffin film and store at $-20^{\circ} \mathrm{C}$.

5. Using the same procedure as above, prepare a stock solution of the test chemistry.

NOTE: Many test chemistries are highly labile, and solutions should preferably be made fresh each time the bioassay is performed.

6. Prepare serial dilutions of the positive control and test chemistries from stock solutions as shown in Figure $\mathbf{5}$ using $20 \mathrm{~mL}$ glass vials previously rinsed with acetone.

7. Purge a $1 \mathrm{~mL}$ glass syringe with acetone, fill with acetone and secure in the micro-applicator adjusted to deliver a volume of $0.25 \mu \mathrm{L}$.

8. Working in batches of ten, remove 3 - 5-day old adult female mosquitoes from cages using an aspirator and anesthetize for up to five min at 4 ${ }^{\circ} \mathrm{C}$ in a fridge or on ice. Next, transfer mosquitoes to a Petri dish and place on ice for up to $10 \mathrm{~min}$.

9. Working quickly, remove a single female with fine tweezers, and apply $0.25 \mu \mathrm{L}$ of test solution to the dorsal thorax using the syringe microapplicator. Confirm delivery of chemistry by observation using a dissecting microscope to ensure each mosquito receives the appropriate volume of test chemistry.

10. Transfer the mosquito to a labeled paper cup resting on ice, and repeat nine times to obtain $n=10$ treated mosquitoes. Seal the mosquitoes in the cup with a mesh square secured with a rubber band, and transfer to a plastic tub or growth chamber under constant conditions of $28{ }^{\circ} \mathrm{C}$ and $75-85 \% \mathrm{RH}$ (on a $12 \mathrm{~h}$ day/12 $\mathrm{h}$ night cycle is preferable).

11. Repeat the above experiment twice to obtain $n=3$ technical replicates (i.e., 30 mosquitoes total) per treatment or control group.

12. Repeat steps $3.7-3.10$ first with the test chemistry and then the positive control. NOTE: Another useful control to include if sufficient mosquitoes are available is a "blank" of 30 anesthetized mosquitoes that do not receive either test chemistry or solvent.

13. Record the number of "dead/non-responsive" mosquitoes at $30 \mathrm{~min}, 60 \mathrm{~min}, 2,24$ and $48 \mathrm{~h}$ post-exposure (or alternative time points) using the score sheet (Table 3). Score mosquitoes as "dead/non-responsive" if they show lack of movement, defined as laying on one side or on the back and with the inability to fly.

14. If desired, correct for control mortality using the modified Abbott's formula as follows: Mortality $(\%)=(X-Y) * 100 /(100-Y)$, where $X=$ the percent mortality in the treated sample, and $Y=$ the percent mortality in the control.

15. Display results as a histogram or an exponential curve. For a dose response assay, calculate the $L D_{50}, L D_{75}$ or $L D_{90}$ value for the test chemistry relative to the control.

16. Repeat the assay at least twice using separate batches of mosquitoes to obtain $n=3$ or more biological replicates.

\section{Adult Blood-Feeding Assay (Single Point Dose or Dose Response Assay)}

1. Collect approximately 150 4-5-day old adult female mosquitoes and transfer to a separate cage. Repeat to obtain 6 cages if performing a dose response assay. Remove the source of sugar 1-24 h prior to the feeding assay.

2. Prepare a stock solution of chemistry as described above, accounting for the purity of the chemistry (a typical stock solution is $80 \mathrm{mM}$ in water or salt buffer), and subsequently prepare serial dilutions in water/buffer as required.

3. Add $40 \mu \mathrm{L}$ of each of the dilutions to $960 \mu \mathrm{L}$ of defibrinated rabbit blood to obtain the desired test concentration. Apply membrane film to a feeding unit and seal with a rubber ring. Transfer $1 \mathrm{~mL}$ of blood via pipette and attach the feeding unit to a heating unit.

4. Gently swab the membrane surface with freshly made $10 \%$ lactic acid solution and place the feeding unit into the cage of adult mosquitoes Cover the cage with a dark cloth or black trash bag and allow mosquitoes to feed for one hour.

5. Repeat steps $4.2-4.4$ for the remainder of test solutions and the negative (blood-only) control.

6. On completion of feeding, place buckets at $4{ }^{\circ} \mathrm{C}$ in a refrigerator for $5 \mathrm{~min}$ to anesthetize mosquitoes. Remove male mosquitoes and non-fed female mosquitoes, and count and record the total number of fed and partially fed mosquitoes by examination of the abdomen.

7. Retain partially and fully fed female mosquitoes, aiming for a minimum of 50 blood-fed mosquitoes per dose.

8. Transfer buckets to a plastic tub or growth chamber under constant conditions of $28{ }^{\circ} \mathrm{C}$ and $75-85 \% \mathrm{RH}$ (on a $12 \mathrm{~h}$ day/12 h night cycle is preferable).

9. Record the total number of dead/non-responsive mosquitoes at $0.5,1,1.5,2,24,48$ and $72 \mathrm{~h}$ (or alternative time-points as desired) using the score sheet (Table 4).

10. On the third day post blood feeding, introduce an egg cup into the cage and collect eggs over a $72 \mathrm{~h}$ period. Count the total number of eggs produced per treatment under a dissecting microscope.

11. Calculate the percent mortality and fecundity as a function of the total number of fed mosquitoes for each treatment group and the control. Correct for control mortality using the modified Abbott's formula if desired.

12. Display toxicity and fecundity data as a histogram plot or exponential curve (if performing a dose response assay) using software of choice. If performing a dose response assay, calculate the $L_{50}$, $L D_{75}$ or $L D_{90}$ value for the test chemistry relative to the control.

13. Repeat the assay at least twice using separate batches of mosquitoes to obtain $n=3$ or more biological replicates. 


\section{Representative Results}

Figure 6 shows the percent mortality of L3 Ae. aegypti following exposure to five doses of the dopamine receptor antagonist, amitriptyline in comparison to the water only (negative) control at 24,48 and $72 \mathrm{~h}$. In this example, the data collected at each of the time-points display a typical logarithmic curve and reveal a dose-dependent effect of amitriptyline on larval mortality. The $\mathrm{LC}_{50}$ value decreases over the time course of the experiment and can be calculated using the $72 \mathrm{~h}$ data (i.e., midpoint of the logarithmic curve).

Figure 7 shows the percent mortality of 3 - 5-day-old adult females Ae. aegypti following exposure to a $400 \mu \mathrm{M}$ dose $(10 \mu \mathrm{g} / \mu \mathrm{L})$ of the dopamine receptor antagonist, amitriptyline and in comparison to the synthetic pyrethroid, bifenthrin-positive control (technical grade; $500 \mathrm{pg} / \mu \mathrm{L}$ ), acetoneonly negative control and untreated mosquitoes (blank). In this example, both amitriptyline and bifenthrin cause significant adult mortality relative to the negative control. Note that adult mortality decreases over time, presumably due to metabolic detoxification of test chemistries.

Figure 8 shows the percent mortality (left y-axis) of 3-5 day old adult female Ae. aegypti fed a blood meal treated with one of four doses of the dopamine receptor antagonist, amitriptyline, and the fecundity (right y-axis; average egg count/female) for the first gonotrophic cycle post exposure in comparison to control mosquitoes (blood-fed only; negative control). The data reveal that there is no significant effect of amitriptyline on adult mortality relative to the control but demonstrate that amitriptyline significantly increases fecundity at the highest dose $(400 \mu \mathrm{M})$.

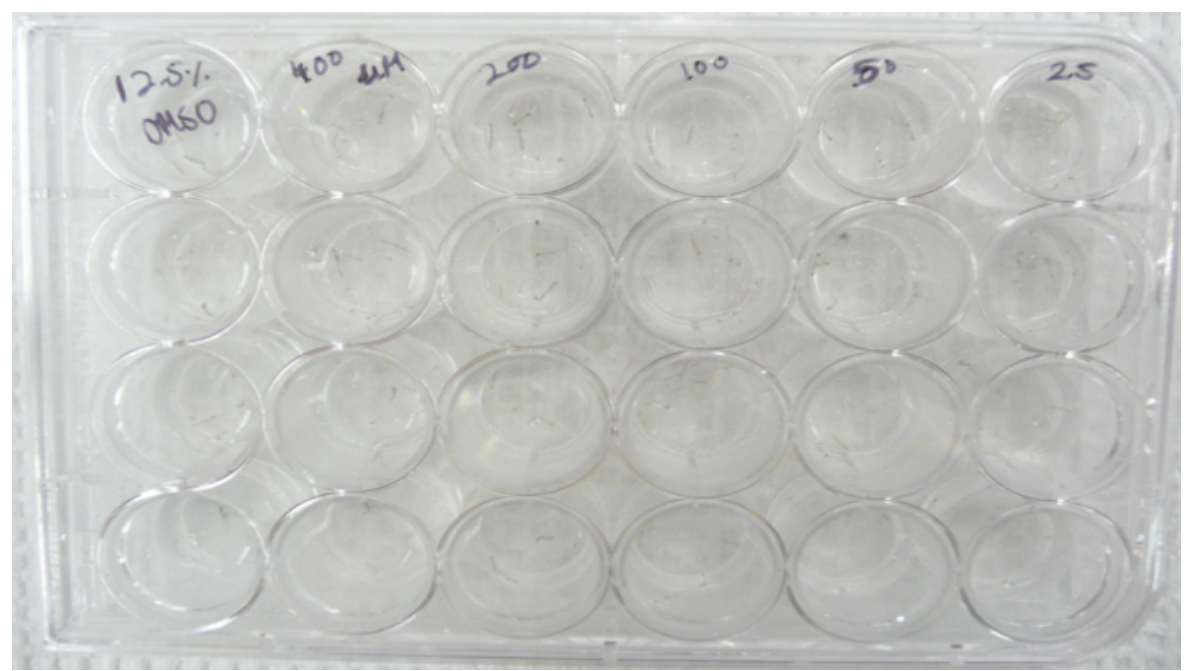

Figure 1. Set-up of the larval dose response assay. Image showing the set-up of the larval dose response assay performed using Aedes aegypti L3 larvae in 24-well plate. 
A

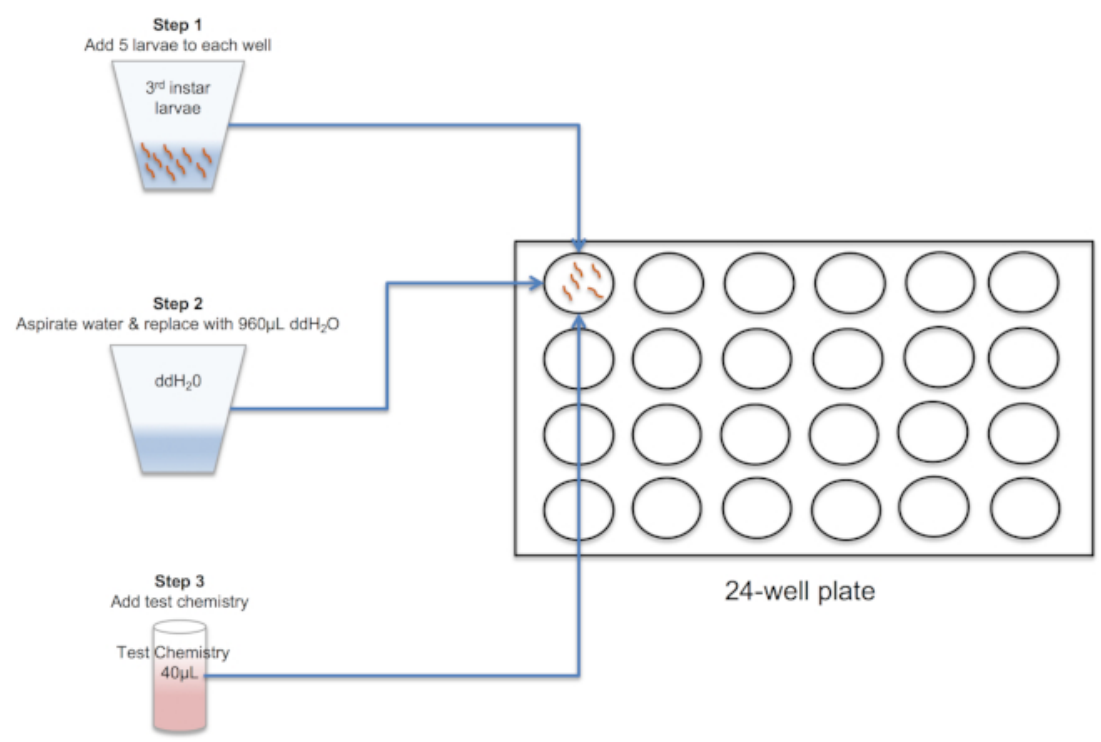

B

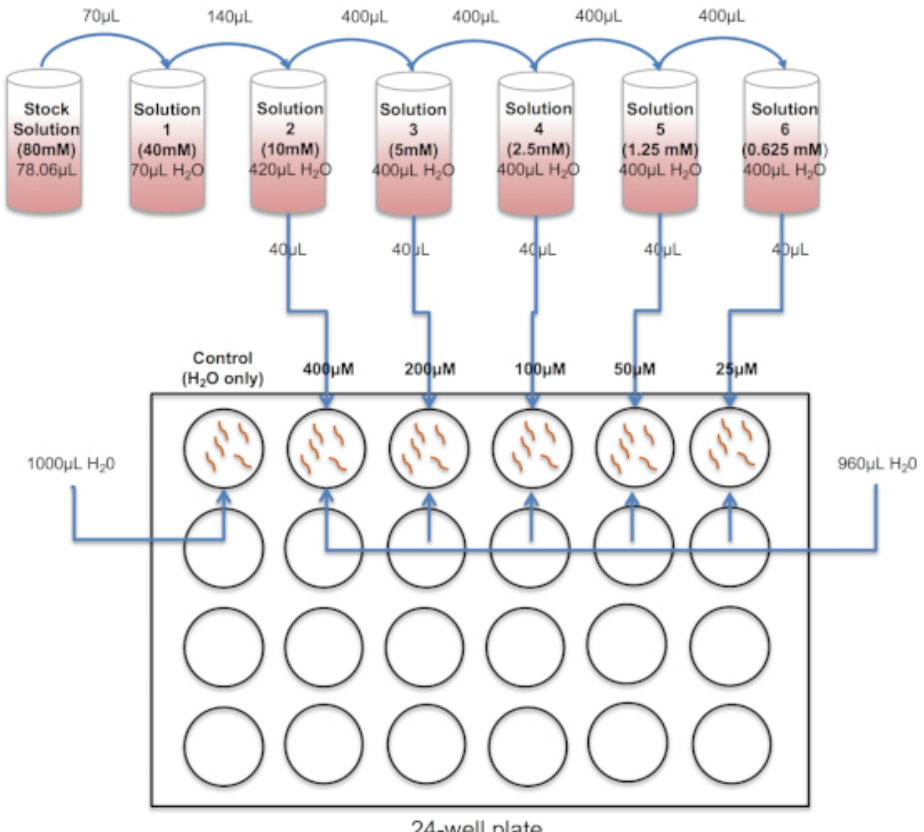

24-well plate

Figure 2. Schematic showing procedure for set up of the (A) single point dose or (B) dose response larval assay in 24-well plate.

Following transfer of five L3 larvae to wells, excess water is gently removed via pipette and replaced with fresh, sterile ddH $\mathrm{H}_{2} \mathrm{O}$. $\mathrm{Next}$, stock and serial dilutions of the test chemistry are prepared and added to a final volume of $1 \mathrm{~mL} /$ well. Please click here to view a larger version of this figure. 


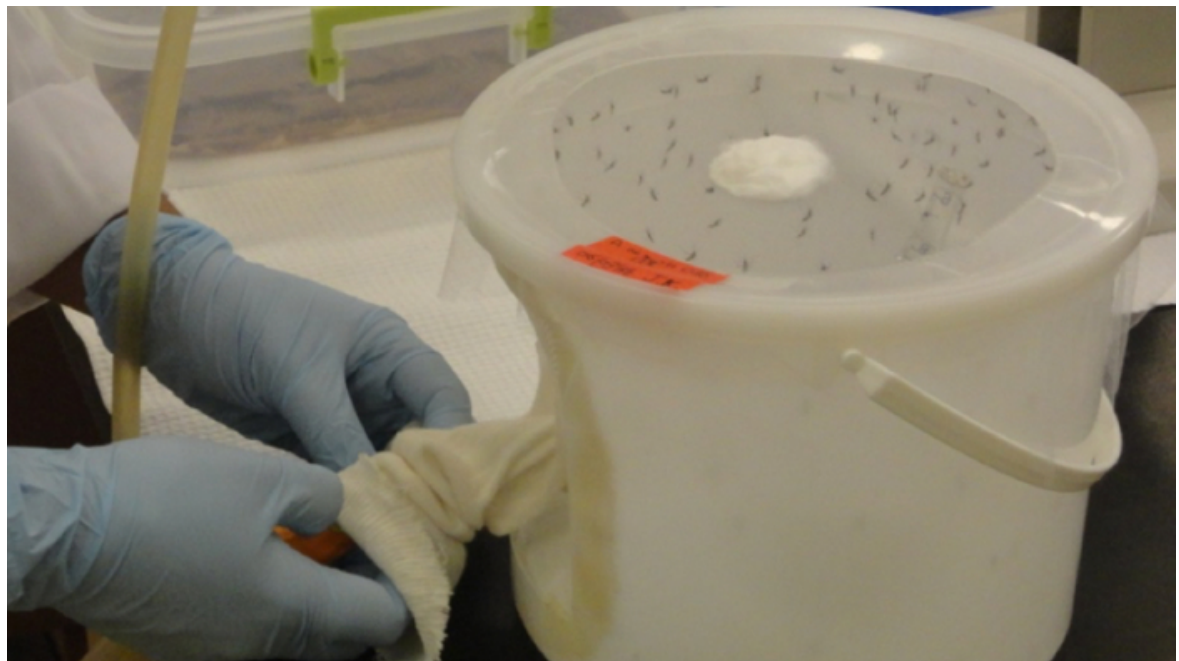

Figure 3. Culture of adult mosquitoes. Image showing $20 \mathrm{~L}$ plastic bucket used for culture of adult mosquitoes and use of an aspirator to remove mosquitoes.

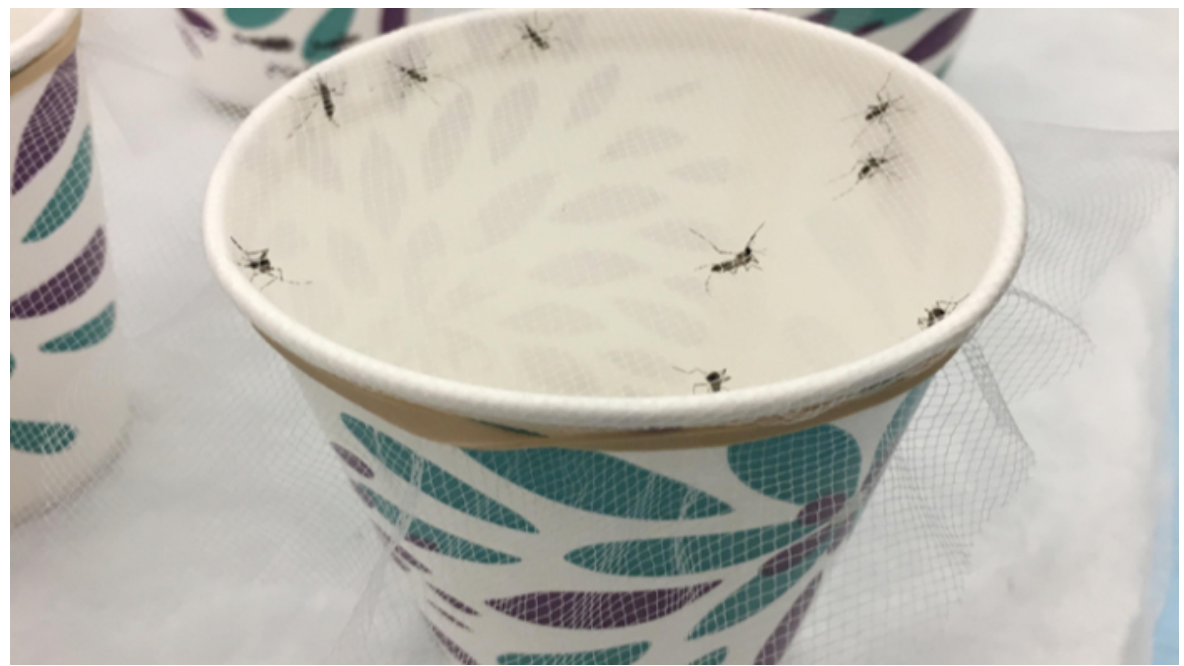

Figure 4. Adult topical assay performed using 4-5 day old female Aedes aegypti. Following treatment with chemistry or solvent, adult mosquitoes are placed in paper cups and transferred to a test chamber for the duration of the assay. 
A.

Dilute $40 \mu \mathrm{L}$ of Solution 1 in $960 \mu \mathrm{L}$ of acetone

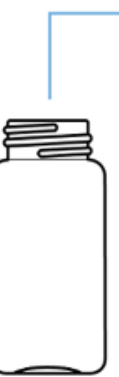

1. Stock Solution $10 \mu \mathrm{g} / \mathrm{mL}$
2. Working Stock $400 \mathrm{ng} / \mu \mathrm{L}$

B.

Solution 3

Dilute $500 \mu \mathrm{L}$ of Solution 2 in $500 \mu \mathrm{L}$ of acetone

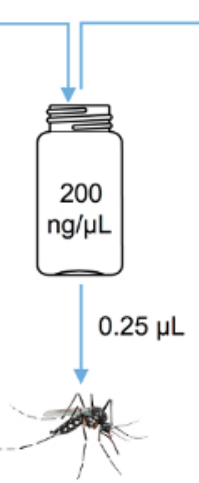

$50 \mathrm{ng} / \mathrm{mosquito}$
Solution 4

Dilute $500 \mu \mathrm{L}$ of Solution 3 in $500 \mu \mathrm{L}$ of acetone

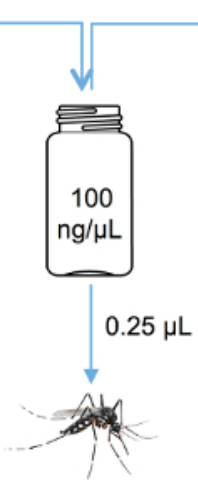

$25 \mathrm{ng} / \mathrm{mosquito}$
Solution 5

Dilute $500 \mu \mathrm{L}$ of

Solution 5 in $500 \mu \mathrm{L}$

of acetone of acetone

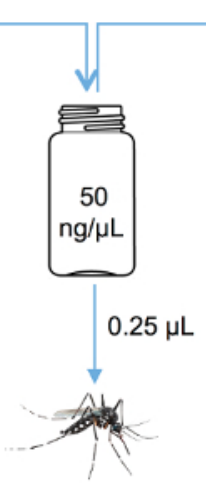

$12.5 \mathrm{ng} /$ mosquito

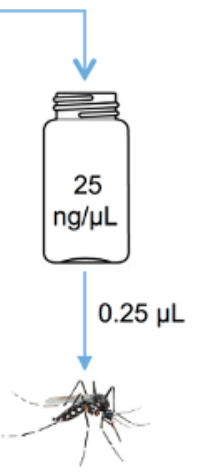

$6.25 \mathrm{ng} /$ mosquito

Figure 5. Stock and serial dilutions. Schematic diagram showing the procedure for preparation of $(\mathbf{A})$ stock and (B) serial test solutions for the adult topical assay. Please click here to view a larger version of this figure.

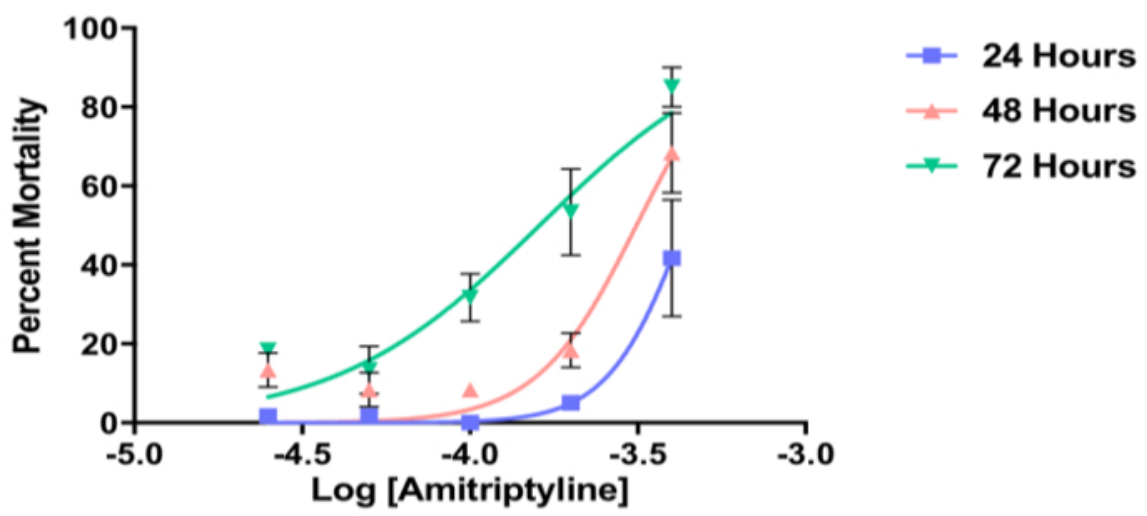

Figure 6. Representative data from a larval contact dose response assay. Representative data from a larval contact dose response assay showing percent mortality of Aedes aegypti L3 larvae following exposure to the dopamine receptor antagonist, amitriptyline at 24,48 and $72 \mathrm{~h}$. Each data point represents mean in $\mu M \pm$ SEM. Data represent $n=3$ biological replicates. 


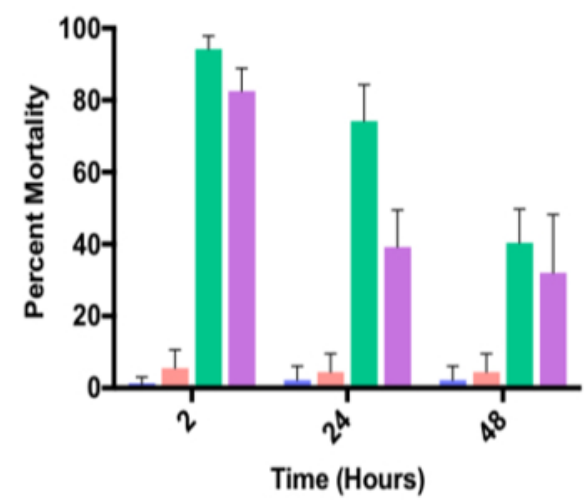

Negative control (blank, no treatment)

Negative control (acetone only)

Bifenthrin $(500 \mathrm{pg} / \mu \mathrm{L})$

Amitriptyline $(10 \mu \mathrm{g} / \mu \mathrm{L})$

Figure 7. Representative data from an adult topical dose response assay. Representative data from an adult topical dose response assay showing toxicity of the dopamine receptor antagonist, amitriptyline $(10 \mu \mathrm{g} / \mu \mathrm{L})$ to $3-5$ day old female Aedes aegypti relative to the synthetic pyrethroid, bifenthrin $(500 \mathrm{pg} / \mu \mathrm{L})$ positive control) and negative control (acetone vehicle only) at 2,24 and $48 \mathrm{~h}$. Data represent $\mathrm{n}=3 \mathrm{biological}$ replicates. Error bars indicate SEM.
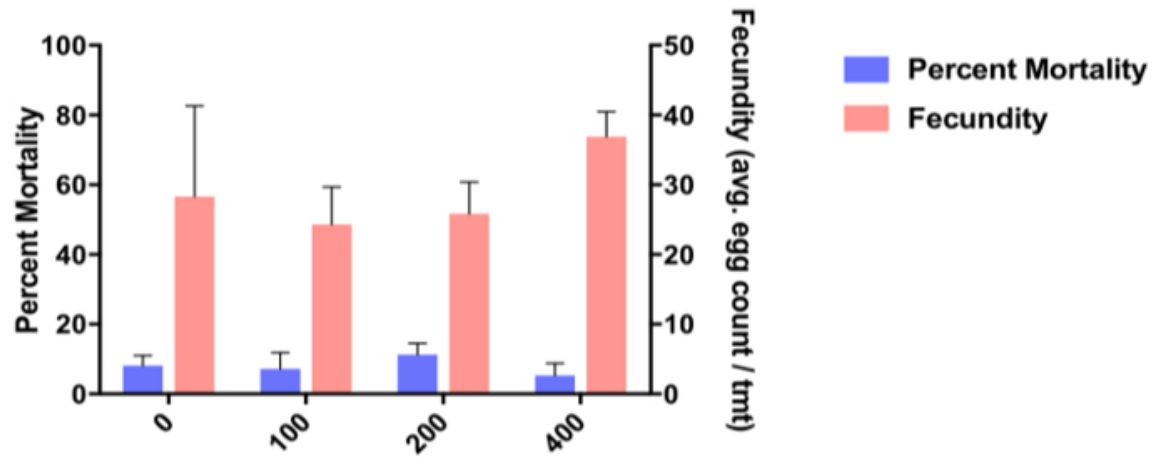

[Amitriptyline], $\mu \mathrm{M}$

Figure 8. Representative data from an adult ingestion assay. Representative data from an adult ingestion assay showing toxicity of the dopamine receptor antagonist, amitriptyline at $100 \mu \mathrm{M}, 200 \mu \mathrm{M}$ and $400 \mu \mathrm{M}$ dose to 3-5 day old adult female Aedes aegypti and impact on fecundity (expressed as the average total egg count per female over the first gonotrophic cycle). Data represent $n=3$ biological replicates \pm SEM.

\begin{tabular}{|c|c|c|c|c|c|}
\hline \multicolumn{6}{|c|}{ A. Single point dose assays with three chemistries } \\
\hline Chemistry & \multicolumn{5}{|c|}{ Concentration (400 uM) } \\
\hline \multirow[t]{2}{*}{ Amitriptyline } & \multicolumn{5}{|c|}{$\begin{array}{l}80 \mathrm{mM} \text { Stock: } 2 \mathrm{mg} \text { of amitriptyline } \times 98 \% \text { (purity of powder) } \times 0.001 \mathrm{~g} / 1 \mathrm{mg} \times 1 \mathrm{~mol} / 313.86 \mathrm{~g} \times 1 \mathrm{~L} / 0.08 \mathrm{~mol} \times 10^{6} \mu \mathrm{L} / \\
\mathrm{L}=78.06 \mu \mathrm{L} \text { of water. }\end{array}$} \\
\hline & \multicolumn{5}{|c|}{$\begin{array}{l}\text { Serial Dilutions: Dilute stock } 1: 2 \text { with } \mathrm{ddH}_{2} \mathrm{O} \text { and then } 1: 4 \text { to achieve } 10 \mathrm{mM} \text {. Add } 40 \mu \mathrm{L} \text { of } 10 \mathrm{mM} \text { stock to well } \\
\text { containing } 960 \mu \mathrm{L} \text { of } \mathrm{ddH}_{2} \mathrm{O} \text { to achieve a final concentration of } 400 \mu \mathrm{M} / \text { well. Prepare serial dilutions of } 10 \mathrm{mM} \text { stock } 1: 2 \text { to } \\
\text { achieve } 5 \mathrm{mM}, 2.5 \mathrm{mM}, 1.25 \mathrm{mM} \text { and } 0.625 \mathrm{mM} \text { stocks. }\end{array}$} \\
\hline \multirow[t]{2}{*}{ Cis-(z)-flupenthixol } & \multicolumn{5}{|c|}{$\begin{array}{l}80 \mathrm{mM} \text { Stock: } 2 \mathrm{mg} \text { of cis }(\mathrm{z} \text { )flupenthixol } X 98 \% \text { (purity of powder) } \times 0.001 \mathrm{~g} / 1 \mathrm{mg} X 1 \mathrm{~mol} / 507.44 \mathrm{~g} \text { cis(z)flupenthixol } X 1 \\
\mathrm{L} / 0.08 \mathrm{~mol} \times 10^{6} \mathrm{\mu L} / \mathrm{L}=48.28 \mu \mathrm{L} \text { of water. }\end{array}$} \\
\hline & \multicolumn{5}{|c|}{ Serial Dilutions: As above. } \\
\hline \multirow[t]{2}{*}{ Amitraz } & \multicolumn{5}{|c|}{$\begin{array}{l}80 \mathrm{mM} \text { Stock: } 2 \mathrm{mg} \text { of Amitraz } \times 0.001 \mathrm{~g} / 1 \mathrm{mg} \times 1 \mathrm{~mol} / 293.4 \mathrm{~g} \text { of amitraz } \times 1 \mathrm{~L} / 0.08 \mathrm{~mol} \times 10^{6} \mu \mathrm{L} / 1 \mathrm{~L}=85.21 \mu \mathrm{L} \text { of } \\
\text { DMSO (note: Amitraz is only soluble in DMSO). }\end{array}$} \\
\hline & \multicolumn{5}{|c|}{ Serial Dilutions: As above. } \\
\hline \multicolumn{6}{|c|}{ B. Dose response assay } \\
\hline \multirow[t]{2}{*}{ Chemistry } & Dose 1 & Dose 2 & Dose 3 & Dose 4 & Dose 5 \\
\hline & $400 \mu \mathrm{M}$ & $200 \mu \mathrm{M}$ & $100 \mu \mathrm{M}$ & $50 \mu \mathrm{M}$ & $25 \mu \mathrm{M}$ \\
\hline \multirow{2}{*}{$\begin{array}{l}\text { e.g., Amitriptyline, } \\
\text { cis-(Z)-flupenthixol or } \\
\text { amitraz }\end{array}$} & $40 \mu \mathrm{L}$ & $40 \mu \mathrm{L}$ & $40 \mu \mathrm{L}$ & $40 \mu \mathrm{L}$ & $40 \mu \mathrm{L}$ \\
\hline & $10 \mathrm{mM}$ stock & $5 \mathrm{mM}$ stock & $2.5 \mathrm{mM}$ stock & $1.25 \mathrm{mM}$ stock & $0.625 \mathrm{mM}$ Stock \\
\hline
\end{tabular}

Table 1. Example calculations for Aedes aegypti L3 larval (A) single point dose assay and (B) dose response assay. 


\begin{tabular}{|c|c|c|c|c|c|c|}
\hline \multicolumn{7}{|c|}{ Mosquito L3 Larval Assay } \\
\hline \multicolumn{7}{|c|}{ Date initiated: } \\
\hline \multicolumn{7}{|c|}{ Investigator: } \\
\hline \multicolumn{7}{|c|}{ Species/Strain: } \\
\hline \multicolumn{7}{|c|}{ Assay Type: Single point dose/dose response } \\
\hline \multicolumn{7}{|c|}{ A. Mortality (No. dead mosquitoes) } \\
\hline $\begin{array}{c}\text { Time } \\
\text { (hours) }\end{array}$ & Dose 1 & Dose 2 & Dose 3 & Dose 4 & Dose 5 & Control \\
\hline \multicolumn{7}{|l|}{0.5} \\
\hline \multicolumn{7}{|l|}{1} \\
\hline \multicolumn{7}{|l|}{1.5} \\
\hline \multicolumn{7}{|l|}{2} \\
\hline \multicolumn{7}{|l|}{2.5} \\
\hline \multicolumn{7}{|l|}{3} \\
\hline \multicolumn{7}{|l|}{12} \\
\hline \multicolumn{7}{|l|}{24} \\
\hline \multicolumn{7}{|l|}{48} \\
\hline \multicolumn{7}{|l|}{72} \\
\hline \multicolumn{7}{|c|}{ B. Percent Mortality } \\
\hline $\begin{array}{c}\text { Time } \\
\text { (hours) }\end{array}$ & Dose 1 & Dose 2 & Dose 1 & Dose 4 & Dose 5 & Control \\
\hline \multicolumn{7}{|l|}{0.5} \\
\hline \multicolumn{7}{|l|}{1} \\
\hline \multicolumn{7}{|l|}{1.5} \\
\hline \multicolumn{7}{|l|}{2} \\
\hline \multicolumn{7}{|l|}{2.5} \\
\hline \multicolumn{7}{|l|}{3} \\
\hline \multicolumn{7}{|l|}{12} \\
\hline \multicolumn{7}{|l|}{24} \\
\hline \multicolumn{7}{|l|}{48} \\
\hline 72 & & & & & & \\
\hline
\end{tabular}

Table 2. Example score sheet used to record data from the mosquito larval dose response assay. Control, water-only or water with $1 \%$ DMSO or other solvent only. Typical doses used to test small molecule antagonist chemistries such as amitriptyline are $25 \mu \mathrm{M}, 50 \mu \mathrm{M}, 100 \mu \mathrm{M}$, $200 \mu \mathrm{M}$ and $400 \mu \mathrm{M}$. 


\begin{tabular}{|c|c|c|c|c|c|c|}
\hline \multicolumn{7}{|c|}{ Mosquito Adult (3-5 day old) Topical Assay } \\
\hline \multicolumn{7}{|l|}{ Date initiated: } \\
\hline \multicolumn{7}{|l|}{ Investigator: } \\
\hline \multicolumn{7}{|c|}{ Species/Strain: } \\
\hline \multicolumn{7}{|c|}{ Assay Type: Single point dose/dose response } \\
\hline \multicolumn{7}{|c|}{ A. Mortality (No. dead mosquitoes) } \\
\hline Time (hours) & Dose 1 & Dose 2 & Dose 3 & Dose 4 & Dose 5 & Control \\
\hline \multicolumn{7}{|l|}{0.5} \\
\hline \multicolumn{7}{|l|}{1} \\
\hline \multicolumn{7}{|l|}{1.5} \\
\hline \multicolumn{7}{|l|}{2} \\
\hline \multicolumn{7}{|l|}{2.5} \\
\hline \multicolumn{7}{|c|}{ B. Percent Mortality } \\
\hline Time (hours) & Dose 1 & Dose 2 & Dose 3 & Dose 4 & Dose 5 & Control \\
\hline \multicolumn{7}{|l|}{0.5} \\
\hline \multicolumn{7}{|l|}{1} \\
\hline \multicolumn{7}{|l|}{1.5} \\
\hline \multicolumn{7}{|l|}{2} \\
\hline 2.5 & & & & & & \\
\hline
\end{tabular}

Table 3. Example score sheet used to record data from the adult topical dose response assay. 


\begin{tabular}{|c|c|c|c|c|c|c|}
\hline \multicolumn{7}{|c|}{ Mosquito Adult (3-5 day old) Ingestion Assay } \\
\hline \multicolumn{7}{|l|}{ Date initiated: } \\
\hline \multicolumn{7}{|l|}{ Investigator: } \\
\hline \multicolumn{7}{|c|}{ Species/Strain: } \\
\hline \multicolumn{7}{|c|}{ Assay Type: Single point dose/dose response } \\
\hline \multicolumn{7}{|c|}{ A. Number Fed Mosquitoes } \\
\hline & Dose 1 & Dose 2 & Dose 3 & Dose 4 & Dose 5 & Control \\
\hline \multicolumn{7}{|l|}{ Fed } \\
\hline \multicolumn{7}{|l|}{ Not Fed } \\
\hline \multicolumn{7}{|l|}{ Total } \\
\hline \multicolumn{7}{|l|}{$\%$ Fed } \\
\hline \multicolumn{7}{|c|}{\begin{tabular}{|l|l}
$\%$ Not Fed & \\
\end{tabular}} \\
\hline \multicolumn{7}{|c|}{ B. Mortality (No. dead mosquitoes) } \\
\hline Time (hours) & Dose 1 & Dose 2 & Dose 3 & Dose 4 & Dose 5 & Control \\
\hline \multicolumn{7}{|l|}{2} \\
\hline \multicolumn{7}{|l|}{24} \\
\hline \multicolumn{7}{|l|}{48} \\
\hline \multicolumn{7}{|l|}{72} \\
\hline \multicolumn{7}{|c|}{ C. Percent Mortality } \\
\hline Time (hours) & Dose 1 & Dose 2 & Dose 3 & Dose 4 & Dose 5 & Control \\
\hline \multicolumn{7}{|l|}{2} \\
\hline \multicolumn{7}{|l|}{24} \\
\hline \multicolumn{7}{|l|}{48} \\
\hline 72 & & & & & & \\
\hline
\end{tabular}

Table 4. Example score sheet used to record data from the adult blood-feeding assay. Typical doses used to test small molecule antagonist chemistries such as amitriptyline are $50 \mu \mathrm{M}, 100 \mu \mathrm{M}, 200 \mu \mathrm{M}$ and $400 \mu \mathrm{M}$.

\section{Discussion}

Insecticides are powerful tools to combat mosquito-borne diseases such as malaria ${ }^{25}$, dengue and Zika ${ }^{26}$. Extensive insecticide use has produced mosquito populations that are resistant to chemical control, leading to the development of insecticide resistance, which is considered the single biggest threat to continued disease control. The last decade has seen a dramatic increase in populations of Anopheles spp. resistant to synthetic pyrethroids (SPs) used in bed nets in Africa ${ }^{7}$. Populations of Aedes albopictus, a vector of dengue and Zika, have been reported in Florida and New Jersey that are resistant to organophosphates ${ }^{6}$. Similarly, resistance to DDT and pyrethroids has been documented in populations of Anopheles and Aedes spp. in Colombia ${ }^{27,28}$. There is urgent need to develop new larvicides and adulticides that bind to diverse orthosteric or allosteric sites on known molecular targets or that disrupt new targets (i.e., novel MoA chemistries) ${ }^{29,30}$ and have minimal environmental impact. There is also increasing recognition of the potential around endectocides for mosquito control $^{31,32,33}$.

To facilitate the rapid development of such products, we describe a series of protocols designed to evaluate the toxicity of small molecule chemistries to mosquito larvae and adults via two delivery routes - contact and ingestion. Protocols such as the WHO susceptibility test and the $\mathrm{CDC}$ bottle assay are in common use for evaluating the toxicity and repellency of existing insecticidal formulations ${ }^{1,2}$. However, these assays have limitations for analyses of unformulated novel chemical entities (NCEs) and are not amenable to testing large numbers of chemistries in moderate or high throughput.

Here we describe a standard larval assay to rapidly evaluate NCEs in single point dose that can scale for high throughput analyses. We also describe an adaption of an assay developed by the LITE $^{21}$ to evaluate the contact toxicity of small molecule chemistries to adult mosquitoes. Finally, we describe an ingestion assay to evaluate toxicity of NCEs delivered via the blood meal to adult female mosquitoes and explore endectocide potential. These larval and adult assays can be performed at a range of doses in order to determine LC and LD values, respectively, and both larval and adult contact assays can be performed in comparison to one or more existing chemical formulations. The adult topical assay also enables the calculation of LD values per individual mosquito. The protocols can be performed using species of Aedes, Anopheles and Culex $^{16,29}$ and could be modified to accommodate the specific biological characteristics of a species, if desired. In our experience, mosquitocidal chemistries typically exhibit broad activity across these three genera ${ }^{16,29}$, but there is value to assessment of species selectivity.

The assays are a starting point to rapidly screen multiple chemistries for insecticidal activity. Those chemistries that exhibit toxicity in one or more assays could be selected for further analyses via secondary and tertiary assays. Examples include the LITE tarsal assay and sugar feeding assays ${ }^{34,35}$. The selection of additional assays is typically determined by considerations around anticipated market and application, with 
results providing insights to possible product delivery modes. In the representative results shown here, we explore the toxicity of amitriptyline, an antagonist of mammalian and invertebrate dopamine receptors that has been evaluated for potential as a novel MoA insecticide ${ }^{10,12,13,16}$. Amitriptyline exhibited toxicity to larvae and adults of $A e$. aegytpi in the $\mu \mathrm{g}$ range suggesting larvicidal and adulticidal activity, and providing rationale for an exploration of an amitriptyline-based chemical series to identify analogues with high potency. No significant effect on mortality or fecundity was observed in Ae. aegypti exposed to amitriptyline in the blood meal. While the stability of the chemistry in defibrinated blood and effective dose received per mosquito is not known, notable limitations of the assay, the data suggest that amitriptyline and other GPCR-active compounds may have little potential as endectocides, at least in unformulated state.

Precautions to limit biological variation between assays are essential. All assays should be performed under standard conditions of temperature and humidity, preferably in an insect growth chamber, in order to ensure reproducibility. It is imperative to standardize procedures for scoring phenotypic end-points as these can be highly subjective, leading to significant variation in data recorded by different laboratory personnel. The larval assay is best suited to evaluation of chemistries that are soluble in water, although the assay can be performed using organic solvents such as DMSO provided that the final concentration is less than $1 \%$ per well. We recognize several limitations to the adult topical assay. First, it is necessary to work rapidly when preparing serial dilutions and delivering doses as the carrier (acetone) is highly volatile and evaporation may produce variation in the amount of chemistry delivered. Second, care should be taken to limit the period of anesthesia as this can contribute to mortality. It should also be noted that solvents such as acetone can produce a rapid "knock-down" effect in the first several hours of the topical assay, which should not be confused with effects due to the test chemistry. We note that the volume of the mosquito blood meal varies between individuals, complicating an assessment of the dose received per adult in the adult ingestion assay. Finally, assay data should not be considered in cases where the mortality in the negative control exceeds $10 \%$.

Products that act synergistically are increasingly recognized for their potential to extend the utility of existing products and provide control of insecticide resistant pest populations ${ }^{15,16,36}$. Larval assays have been used to examine synergism between the formamidine pesticide, amitraz and a variety of chemistries that disrupt invertebrate octopamine receptors ${ }^{14,15}$. The larval assay and adult topical assay described are suitable for evaluating synergistic or additive effects between combinations of test chemistries. We note that synergists such as piperonyl butoxide (PBO) can be incorporated into each of the three assays described here.

The above-described assays provide a standardized experimental series for evaluation of unformulated, small molecule drugs against aquatic and terrestrial mosquito life stages. These assays are specifically designed to evaluate toxicity and offer several advantages over existing assays in common use. Importantly, the assays are amenable to automation and can be performed at industrial scale to enable evaluation of thousands of test compounds. Lastly, as the field considers the development of products that act via new MoAs, including via disruption of novel molecular targets and biochemical pathways, it will be essential to score multiple phenotypic endpoints in addition to those such as mortality and paralysis. The above assays permit such investigations, thus providing a step towards tomorrow's highly innovative insecticidal technologies.

\section{Disclosures}

The authors declare no conflicts of interest.

Acknowledgments

The authors thank H. Ranson, Liverpool School of Tropical Medicine for assistance with assay development and provision of the LITE protocol, and M. Scharf, Purdue University for advice regarding assay design.

\section{References}

1. World Health Organization. A global brief on vector-borne diseases. Available from: www.who.int/about/Licensing/copyright_form/en/ (2014).

2. World Health Organization. Vector-borne diseases. Available from: http://www.who.int/mediacentre/factsheets/fs387/en/ (2016).

3. World Health Organization. Report by the Secretariat. Neglected tropical diseases; Prevention, control, elimination and eradication. Available from: http://www.who.int/neglected_diseases/A66_20_Eng.pdf (2013).

4. Tolle, M. A., et al. Mosquito-borne diseases. Curr Probl Pediatr Adolesc Health Care. 39 (4), 97-140 (2009).

5. Chen, C. D., et al. Dengue vectors surveillance in endemic areas in kuala lumpur city centre and selangor state, malaysia. Dengue Bulletin. 30 (2006).

6. Marcombe, S., et al. Insecticide resistance status of united states populations of Aedes albopictus and mechanisms involved. PLoS ONE. 9 (7), e101992 (2014).

7. Ranson, H., et al. Pyrethroid resistance in African anopheline mosquitoes: what are the implications for malaria control? Trends in Parasitology. 1-8 (2010).

8. Hemingway, J., Ranson, H. Insecticide resistance in insect vectors of human disease. Annual Review of Entomology. 45, 371-91 (2000).

9. Hemingway, J., Beaty, B. J., Rowland, M., Scott, T. W., Sharp, B. L. The Innovative Vector Control Consortium: improved control of mosquitoborne diseases. Trends in Parasitology. 22 (7), 308-12 (2006).

10. Meyer, J. M., et al. A "genome-to-lead" approach for insecticide discovery: Pharmacological characterization and screening of Aedes aegypti D 1-like dopamine receptors. PLOS Neglected Tropical Diseases . 6 (1), e1478 (2012).

11. World Health Organization. Instructions for determining the susceptibility or resistance of mosquito larvae to insecticides. Avaialable from: http://apps.who.int/iris/handle/10665/69615 (1981).

12. Hill, C. A., et al. Re-invigorating the insecticide discovery pipeline for vector control: GPCRs as targets for the identification of next gen insecticides. Pestide Biochemistry and Physiology. 106 (3), 141-148 (2013).

13. Conley, J. M., et al. Evaluation of AaDOP2 Receptor antagonists reveals antidepressants and antipsychotics as novel lead molecules for control of the yellow fever mosquito, Aedes aegypti. Journal of Pharmacology and Experimental Therapeautics. 352 (1), 53-60 (2015). 
14. Ahmed, M. A. I., Matsumura, F. Synergistic actions of formamidine insecticides on the activity of pyrethroids and neonicotinoids against Aedes aegypti (Diptera: Culicidae). Journal of Medical Entomology. 49 (6), 1405-10 (2012).

15. Ahmed, M. A. I., Vogel, C. F. A. Synergistic action of octopamine receptor agonists on the activity of selected novel insecticides for control of dengue vector Aedes aegypti (Diptera: Culicidae) mosquito. Pesticide Biochemistry and Physiology. 120, 51-6 (2015).

16. Hill, C. A., et al. Comparative pharmacological characterization of D1-like dopamine receptors from Anopheles gambiae, Aedes aegypti and Culex quinquefasciatus suggests pleiotropic signaling in mosquito vector lineages. Parasites Vectors. 9 (1), 192 (2016).

17. Centers for Disease Control and Prevention. Guideline for evaluating insecticide resistance in vectors using the CDC bottle bioassay. Available from: https://www.cdc.gov/malaria/resources/pdf/fsp/ir_manual/ir_cdc_bioassay_en.pdf (2011).

18. World Health Organization. Test procedures for insecticide resistance monitoring in malaria vector mosquitoes. Available from: http:/l apps.who.int/iris/bitstream/10665/250677/1/9789241511575-eng.pdf (2013).

19. Geneva: World Health Organization. Guidelines for efficacy testing of insecticides for indoor and outdoor ground-applied space spray applications control of neglected tropical diseases who pesticide evaluation scheme. Available from: http://www.who.int/iris/ handle/10665/70070, 2-53 (2009).

20. Pridgeon, J. W., et al. Susceptibility of Aedes aegypti, Culex quinquefasciatus Say, and Anopheles quadrimaculatus Say to 19 pesticides with different modes of action. Journal of Medical Entomolog. 45 (1), 82-7 (2008).

21. Liverpool Insect Testing Establishment. http://www.lite-testing-facility.com (2018).

22. Aïzoun, N., et al. Comparison of the standard WHO susceptibility tests and the CDC bottle bioassay for the determination of insecticide susceptibility in malaria vectors and their correlation with biochemical and molecular biology assays in Benin, West Africa. Parasites Vectors. 6, 147 (2013).

23. Owusu, H. F., Jančáryová, D., Malone, D., Müller, $P$. Comparability between insecticide resistance bioassays for mosquito vectors: time to review current methodology? Parasites Vectors. 8, 357 (2015).

24. Savignac, R., Maire, A. A simple character for recognizing second and third instar larvae of five Canadian mosquito genera (Diptera: Culicidae). (1981).

25. Bhatt, S., et al. Coverage and system efficiencies of insecticide-treated nets in Africa from 2000 to 2017. eLife. 4, 174 (2015).

26. Zaim, M., et al. Alternative insecticides: an urgent need. Trends in Parasitology. 18 (4), 161-3 (2002).

27. Fonseca, I., Quinoñes, M. L. Resistencia a insecticidas en mosquitos (Diptera: Culicidae): mecanismos, deteccion y vigilancia en salud publica. Revista Colombiana de Entomologia. 31 (2), 107-115 (2005).

28. Fonseca-Gon Alez, I., Qu, M. L., Lenhart, A., Brogdon, W. G. Insecticide resistance status of Aedes aegypti (L.) from Colombia. Pest Management Science. 67, 430-437 (2011).

29. Nuss, A. B., et al. Dopamine receptor antagonists as new mode-of-action insecticide leads for control of Aedes and Culex mosquito vectors. PLOS Neglected Tropical Diseases . 9 (3), 1-19 (2015).

30. Shidrawi, G. R. A WHO Global Programme for monitoring vector resistance to pesticides. Bulletin of the World Health Organization. 68 (4), 403 (1990).

31. Sylla, M., Kobylinski, K. C., Foy, B. D. Gates grand challenges explorations award: endectocides for controlling transmission of mosquitoborne diseases. Malariaworld Journal. 4 (5) (2013).

32. Foy, B. D., Kobylinski, K. C., da Silva, I. M., Rasgon, J. L., Sylla, M. Endectocides for malaria control. Trends in Parasitology. 27 (10), $423-8$ (2011).

33. Chaccour, C. J., et al. Ivermectin to reduce malaria transmission: a research agenda for a promising new tool for elimination. Malaria Journal. $12(1), 153$ (2013).

34. Olson, D. M., Fadamiro, H., Lundgren, J. G., Heimpel, E. Effects of sugar feeding on carbohydrate and lipid metabolism in a parasitoid wasp. Physiol Entomol. 25, 17-26, (2000).

35. World Health Organization. Report of the WHO Informal Consultation. Evaluation and testing of insecticides. Avaialble from: http:// www.who.int/whopes/resources/ctd_whopes_ic_96.1/en/ (1996).

36. Huang, Q., Deng, Y., Zhan, T., He, Y. Synergistic and antagonistic effects of piperonyl butoxide in fipronil-susceptible and resistant rice stem borrers, Chilo suppressalis. Journal of Insect Science. 10, 182 (2010). 